\title{
artículos
}

\section{El concepto de ciencia de la documentación: unidad en la diversidad o diversidad en la unidad}

\author{
José López Yepes \\ Escuela Universitaria de Biblioteconomía y \\ Documentación Universidad Complutense \\ de Madrid. Av. Puerta de Hierro s/n, \\ carretera de la Coruña, Km. 6700, C.U. Ma- \\ drid, España. \\ E-mail:lopez-yepes@coelo.eubd.ucm.es
}

\begin{abstract}
RESUMEN
$\boldsymbol{E}_{1}$ autor afirma que la Bibliotecología (Documentación en su terminología) es una ciencia y que existe un paradigma común para la comunidad científica que trabaja en esa área. La Documentación posee la doble vertiente de la unidad en la diversidad y de la diversidad en la unidad, y se tiene como núcleo integrador la investigación científica a la cual sirve: es una ciencia para la ciencia. El objeto de estudio de la Documentación es la información documental, pero con un marcado carácter teleológico. Se expresa la tesis de que la Documentación es la ciencia general que estudia el proceso informativo de adecuación y transmisión de las fuentes para la obtención de nuevo conocimiento.
\end{abstract}

\section{ABSTRACT}

$\boldsymbol{T}$ he author states that library science (in his terminology, documentation) is a science and that exists a common paradigm for the scientific community that works in that area. Documentation posses the double flowing of unity in diversity and diversity in unity, and has its integrator nucleous the scientific research to whom it serves: Is a science for the science itself. The object of study of documentation is the documental information, but with a strong teleological character. It is proposed the thesis that documentation is the general science that studies the informative process of adequation and transmission of sources to obtain new knowledge.

$\boldsymbol{E}$ l XIV Coloquio de Investigación bibliotecológica convocado por el Centro Universitario de Investigaciones Bibliotecológicas de la UNAM (Ciudad de México, junio de 1996) ha constituido, sin duda, un excelente marco y una meritoria iniciativa para la reflexión acerca de un problema permanente, que es la delimitación epistemológica de la Bibliotecología en el sentido amplio en que es entendido en el país hermano. La reflexión que ahora sigue, parte del texto aportado a este evento por el Dr. Rendón — coor- dinador del mismo- - y de algún otro trabajo suyo anterior. 1

\section{PARADIGMA Y CIENCIA}

Se trata, en primer lugar, de plantear un enfoque paradigmático de la ciencia bibliotecológica (documental para nosotros) desde la doble vertiente de unidad en la diversidad o de diversidad en la unidad para llegar a un concepto de la disciplina que nos ocupa $y$, consiguientemente, a su definición. De acuerdo con Rendón, no parece posible movernos en el concepto restrictivo kuhniano de para- digma $^{2}$ sino más bien entendido como sinónimo de corriente, escuela, marco teórico.

Creo firmemente que existe un paradigma de nuestra disciplina, una comunidad científica determinada, a pesar de las diferencias de carácter terminológico y de contenido todos nos entendemos por medio de la lectura de los trabajos y de las intervenciones en las reuniones científicas. Otras causas de la ausencia de paradigma estricto radican, probablemente, en el diverso origen social y académico de las profesiones informativas, en el ob-

1 Miguel Ángel Rendón Rojas. "Las tareas de la fundamentación de la bibliotecología”. En Investigación bibliotecológica, 8,17 julio-diciembre 1994. pp. 4-9 y "Los diferentes enfoques paradigmáticos de la ciencia bibliotecológica unidad en la diversidad o diversidad en la unidad". En XIV Coloquio de Bibliotecología. Ciudad de México, UNAM, CUIB, junio de 1996, inédito (se publica en este número).

2 "Un paradigma está constituido por los supuestos teóricos generales, las leyes, las técnicas e instrumentos aptos para investigar aceptados por la comunidad científica..." M.A. Rendón. "Los diferentes enfoques..." En Op. cit. p. 1. 


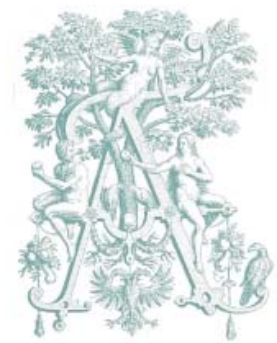

\section{En cuanto a su prerrogativa de ciencia, creemos que una disciplina ya goza de la veste científica cuando pretende serlo, cuando se incorpora a los estudios universitarios y se hace más científica y, en consecuencia, más rigurosa a medida que se ofrecen explicaciones de sus problemas por la vía de la investigación}

jeto multipolar de que consta el documento y, en general, en el cambiante objeto de estudio de la Documentación merced a la mutación de las necesidades sociales y al efecto de la aplicación de las nuevas tecnologías.

En cuanto a su prerrogativa de ciencia, creemos que una disciplina ya goza de la veste científica cuando pretende serlo, cuando se incorpora a los estudios universitarios y se hace más científica y, en consecuencia, más rigurosa a medida que se ofrecen explicaciones de sus problemas por la vía de la investigación. La relativa juventud de nuestra rama del saber corre pareja con el correspondiente grado de plenitud, como ciencia en algunos de sus contenidos, o de técnica en otros. No sería ocioso recordar ahora a Otlet, primer definidor de la Documentación, que la entendía como ciencia, como técnica y como organización.

\section{UNIDAD EN LA DIVERSIDAD}

En un principio, en su momento fundacional otletiano, la Documentación era una en la diversidad por cuanto perseguía la correcta transmisión de las fuentes del conocimiento sobre la base de actuaciones predocumentarias derivadas de la función tradicional de los depósitos de documentos (archivos, bibliotecas, museos, etcétera) o de las incipientes formas de difusión de información (bibliografías, resúmenes de las publicaciones periódicas de carácter científico, etcétera). Otlet trató de formular un concepto integrador de la nueva disciplina en relación con las actividades citadas teniendo como motivación la investigación científica y la resolución del problema de las fuentes implícito en los investigadores. Desde esta perspectiva, el sociólogo belga definía Documentación como "disciplina general, auxiliar de todas las demás, que les impone sus normas desde el momento en que ellas transmiten sus resultados en forma de documentos". 3

Esta definición global de Otlet expresa y fundamentada de modo fehaciente en su Tratado de Documentación permite establecer las siguientes notas: a) La Documentación es la disciplina del documento.

b) La Documentación es ciencia integradora de otras anteriores como la Archivología, la Biblioteconomía, la Museología, etcétera las que presta la función informativa dinámica de los documentos custodiados.

c) La Documentación es una ciencia para la ciencia, al ser un instrumento de crecimiento y transmisión de todos los saberes.

Como se sabe, el concepto integrador otletiano se fragmentó y dio lugar a una serie de enfoques o perspectivas delimitadoras de la Documentación, ahora marcada por un proceso de reagrupamiento en forma de área interdisciplinar de conocimientos. 4

\section{DIVERSIDAD EN LA UNIDAD}

Parece llegado el momento, como decíamos, de considerar que caminamos hacia una convergencia de saberes documentarios que han de desembocar en la configuración pragmática de nuestra disciplina. Desde nuestro punto de vista, la misma:

a) No es, en sus orígenes, como se ha visto, una rama desgajada de un tronco común sino resultado de reintegración de disciplinas anteriores y posteriores, documentarias y no documentarias.

b) Es autónoma, como área independiente de conocimientos e instrumental al servicio del resto de los saberes.

c) Es ciencia informativa, de carácter social, con una función mediadora entre el creador de la información y el usuario de la misma. Dicha función mediadora se lleva a cabo sobre dos ejes: las necesidades de información y el instrumento denominado documento.

d) Su ubicación definitiva en el sistema de las ciencias y, por tanto, su proyecto paradigmático debe hacerse, a nuestro entender, sobre la noción de información documental, un tipo especial de información que se genera y se transmite en el llamado proceso informativo-documental, objeto de estudio, a la postre de la disciplina. ${ }^{5} \mathrm{Si}$ 


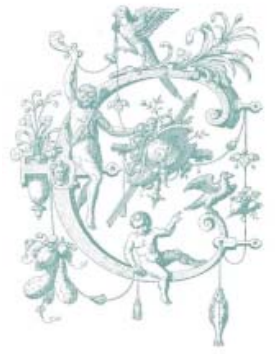

\section{Parece llegado el momento de considerar que caminamos hacia una convergencia de saberes documentarios que han de desembocar en la configuración pragmática de nuestra disciplina}

vale entender la información, en líneas generales, por la puesta en forma o adecuación de un mensaje de un modo determinado para su transmisión a través de un medio determinado, cabe pensar que la información documental es también un peculiar modo informativo que utiliza determinados medios informativos. Así, la información documental lo es porque se vehicula en un soporte físico y también porque es una información que se consume en la toma de decisiones o se conserva y transmite como fuente potencial de nuevas informaciones.

\section{NOMBRE, CONCEPTO Y DEFINICIÓN DE LA DISCIPLINA}

Aludíamos al principio de este texto al problema de la denominación de la disciplina: Bibliotecología, Documentación, Ciencia de la Información son algunas de las denominaciones más usuales. Se ha hablado, y con razón, de una explosión terminológica en tal sentido. Lo deseable, como han expresado Woledge y Schrader, ${ }^{6}$ sería llegar a un término que explicara un solo concepto. Estamos en esta tarea pues de ella depende, grandemente, que el resto de las tareas - como las de carácter formativo, por ejemplose lleven a la práctica con mayor rigor. En mi país, España, hemos llegado a registrar hasta veintitrés términos; de ellos los más usuales son Biblioteconomía y Documentación, Documentación e Información y Documentación. ${ }^{7}$

En cuanto a los posibles criterios que postulamos para el establecimiento del concepto y posterior definición de la Documentación, nos permitimos sugerir los siguientes:

a) Constituyen los orígenes de la disciplina la investigación científica, la obtención de nuevo conocimiento en general y la obtención de información para la acertada toma de decisiones personales o en el seno de una organización.

b) El objeto de estudio es un tipo de información llamado información documental que se genera y se transmite en el proceso de información documental. En dicho proceso se recuperan informaciones previamente emitidas que, debidamente transformadas, se ponen a disposición de un usuario como fuente potencial de nuevas informaciones.

c) Hay un marcado carácter teleológico en la actividad documental. El proceso documental se inicia para satisfacer una determinada necesidad de información y es un proceso altamente operativo, pues sólo tiene sentido cuando se pone al servicio de una disciplina o actividad social determinadas, es decir, cuando se torna especializada.

A la hora de definir Documentación, hemos afirmado en otro lugar, ${ }^{8}$ y ahora nos reiteramos en ello, que esta disciplina puede entenderse:

a) Como conjunto de disciplinas del documento o Ciencias de la Documentación o aquellas que estudian y ejecutan los diversos aspectos del proceso documental (Archivología, Bibliotecología, Documentación, propiamente dicha, Museología, Bibliografía, Bibliometría, etcétera)

b) Como disciplina responsable del estudio de una parte del proceso documental que afecta esencialmente a la fase de recuperación y difusión de la información.

De modo sintético, podemos entender que documentación es la ciencia general que tiene por objeto de estudio el proceso informativo de adecuación y transmisión de las fuentes para la obtención de nuevo conocimiento.

5 - José María Desantes Guanter. Teoría y régimen jurídico de la documentación. Madrid, Eudema, 1987.\par —Juan Antonio Martínez Comeche. Teoría de la información documental y de las instituciones documentales. Madrid, Síntesis, 1995, 182p.

6 - Woledge G. "Bibliography and Documentation : Words and Ideas." En Journal of documentation. 39, 4, diciembre 1983, pp. 266-279.|par - Alvin M. Schrader. "Search of a Name: Information Science and its Conceptual Antecedents." En Library and Information Science Research. 6, 1984, pp. 247-248.

7 Ejemplos de la triple denominación en España los encontramos en los títulos universitarios —de Diplomado en Biblioteconomía y Documentación y de Licenciado en Documentación - y en las publicaciones periódicas Revista española de documentación científica (editada por el Consejo Superior de Investigaciones Científicas) y Revista general de información y documentación (editada por la Universidad Complutense de Madrid), además del Manual de información y documentación (publicado por Editorial Pirámide, de Madrid en 1996).

8 José López Yepes. Op. cit. 